\title{
SEISMIC BEHAVIOUR OF A REINFORCED CONCRETE PORTAL FRAME SUSTAINING GRAVITY LOADS
}

\author{
L.M. Meggett* and R.C. Fenwick*
}

\begin{abstract}
SUMMARY
To study the behaviour of multistorey building frames under gravity and severe earthquake conditions a reinforced concrete portal frame was constructed. The beam was subjected to constant vertical loads while a cyclic lateral load was applied to the unit. Negative moment plastic hinges formed at the column faces while the positive moment hinges were located in the span. The rotations generated by each inelastic displacement accumulated. This placed high rotational demands on the plastic hinges, which reduced the overall ductile behaviour compared with that observed in typical beam-column sub-assembly tests. The high rotations caused the beam to grow in length.
\end{abstract}

Editors Note: This paper was first published in the Proceedings of the 1988 Pacific Concrete conference and is reprinted with the permission of the cement and Concrete Association of New Zealand and the New Zealand Concrete Society.

\section{INTRODUCTION}

In a previous paper [1] it was shown that extensive redistribution of gravity actions can occur in a frame structure when plastic hinges are formed. Two different cases were identified for seismic resistant frames designed to form a beam sway as distinct from a column sway mechanism. These are described in the following two paragraphs.

In the first of these, where the gravity moments are small compared with the seismic moments, positive and negative plastic hinges form in the beams at the column faces. As the structure sways backwards and forwards the sign of the plastic rotation in each hinge zone changes, with negative rotations tending to cancel the positive rotations. In this case the maximum rotational demand on the hinge zone is associated with the maximum rotation of the columns sustained during the earthquake. On removal of the lateral load it is found that moment redistribution causes the column face moments under gravity actions to be zero, as is illustrated in Figure la.

In the second of these cases either higher gravity moments relative to the seismic actions, or different distributions of reinforcement in the beam, leads the positive and negative moment hinges to form at different locations. This case is illustrated in Figure lb. Negative hinge zones form at the column faces and positive hinge zones in the beam span. With these non-reversing hinges the total rotational demand depends on the sum of all the inelastic rotational demands arising from each inelastic displacement. Thus during

* Department of Civil Engineering, University of Auckland the passage of the earthquake the hinge rotations accumulate and the vertical deflection of the beam progressively increases. It was felt [1] that the high rotational demands on such hinge zones might reduce the ductility of the structure. With this type of behaviour the rotational demand is no longer related to the rotation of the column or the displacement ductility of the structure, but instead it is related to the total energy that the beam must dissipate by yielding during the earthquake (or earthquakes) it is designed to survive. Designing for a given ductility gives little guidance for this form of structure.

This paper describes the construction and testing of a reinforced concrete portal frame, which was designed to form nonreversing plastic hinge zones, under cyclic inelastic lateral loading.

\section{PORTAL FRAME TEST SPECIMEN}

A reinforced concrete pin ended portal frame with a span in excess of five metres was built in the laboratory, as illustrated in Figure 2. This unit was modelling part of a multi-storey frame structure, which was proportioned to form a beam sway mechanism under severe seismic conditions. As far as possible the unit was designed to comply with the NZ Concrete Code (NZS 3101) [2]. To ensure that plastic hinges formed in the beams the columns and joint zones were detailed to remain elastic under overstrength actions. To prevent the yielding of the flexural reinforcement in the plastic hinges from spreading into the joint zones, Dlo bars were fillet welded to this steel. The reinforcement details are shown in Figure 3. 


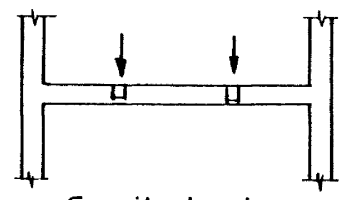

Gravity loads

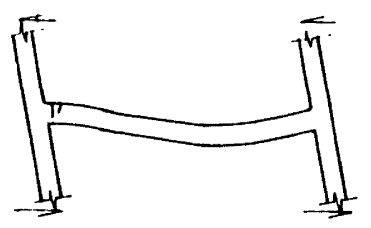

1st hinge forms

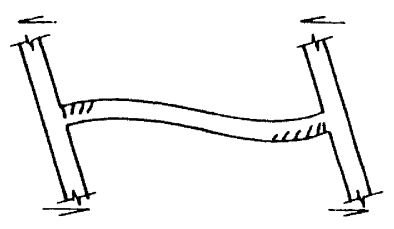

2nd hinge forms

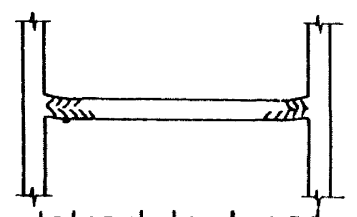

Lateral load and column deflection removed

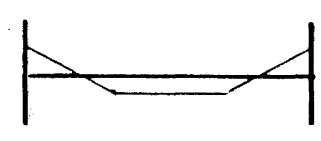

Gravity actions

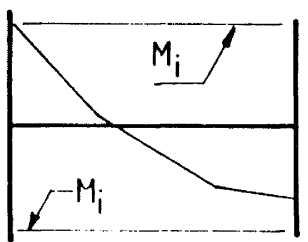

1st hinge forms

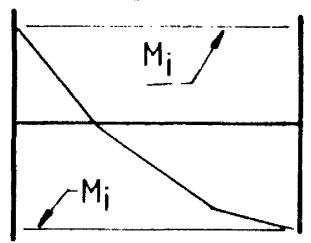

2nd hinge forms

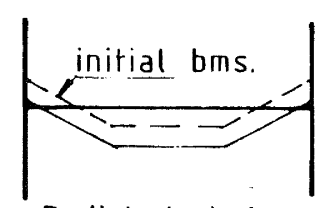

Redistributed gravity bms.

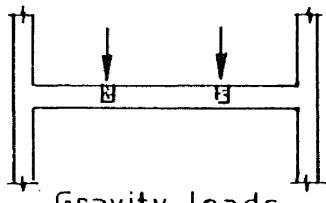

Gravity loads

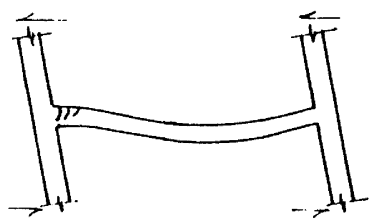

1st. hinge forms

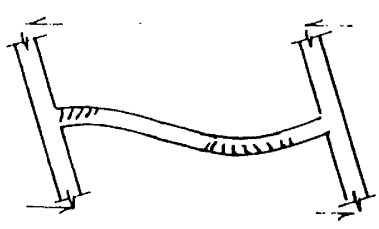

2 nd. hinge forms

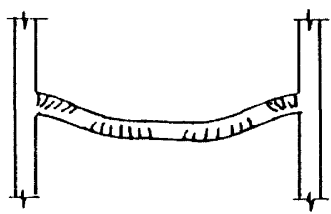

Lateral load and column deflection removed

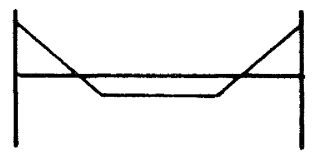

Gravity actions

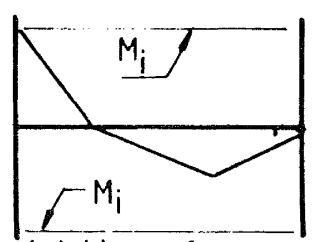

1st hinge forms

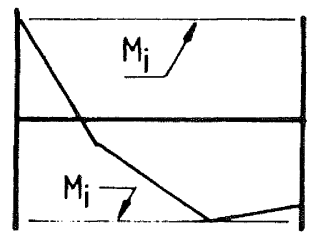

2 nd. hinge forms

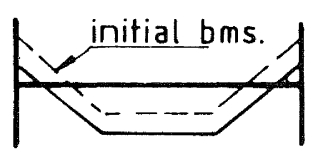

Redistributed gravity bms.
FIGURE IA. POSITIVE AND NEGATIVE HINGES AT COLUMN FACE
FIGURE 1B. POSITIVE AND NEGATIVE HINGE ZONES SEPARATED
The beam in the portal frame was subjected to two constant vertical loads during the test. The portal frame was proportioned so that under the action of these loads, together with cyclic lateral loading, negative moment hinges would form in the beam close to the column faces while positive moment hinges would form near the vertical load points.

The frame was cast on its side in a single pour and moist cured for ten days before it was lifted into the upright position and prepared for testing. The concrete was purchased from a local ready mix supplier and at the time of test the cylinder strength was $44.9 \mathrm{MPa}$. Tests on the reinforcement showed that the yield stress levels in the D24 and D28 bars were 332 and $317 \mathrm{MPa}$ respectively, while $\mathrm{D} 2 \mathrm{OH}$ column bars had a yield stress of $490 \mathrm{MPa}$. The round $10 \mathrm{~mm}$ bars used as stirrup reinforcement in the beam and columns had a yield strength of $354 \mathrm{MPa}$.

During the test the vertical reactions on the columns were resisted by roller bearings while the horizontal reactions were taken out separately through pin ended members. A load cell was incorporated in each of these to allow the horizontal reaction to be measured. The vertical loads on the beam were applied by two jacks acting in tension. To keep these loads near constant at $120 \mathrm{kN}$ each, an accumulator was built into the hydraulic circuit. The load levels were monitored at regular intervals and adjusted at the start of each loading cycle. The maximum range of variation was 96 to $130 \mathrm{kN}$. The reversing lateral load was applied near the top of one column (400 mm above the beam's centreline), with the jack reaction being taken by the test wall. To prevent a failure due to instability of the portal, when the plastic hinges formed, both columns were restrained against movement out of the plane of the portal. This was achieved by attaching $3 \mathrm{~m}$ long pin ended struts to the columns at right angles to the axis of the beam.

To test the member the vertical load was applied first then two lateral load cycles were applied to a load level of plus and minus 0.75 of the calculated load required to form the first plastic hinge (referred to as "L" in the figures). From the load displacenent measurements the ductility 1 (DI) displacement was assessed by projecting a line drawm through the load deflection curves to the theoretical lateral load ultimate strength. Subsequent testing was controlled by the displacement 


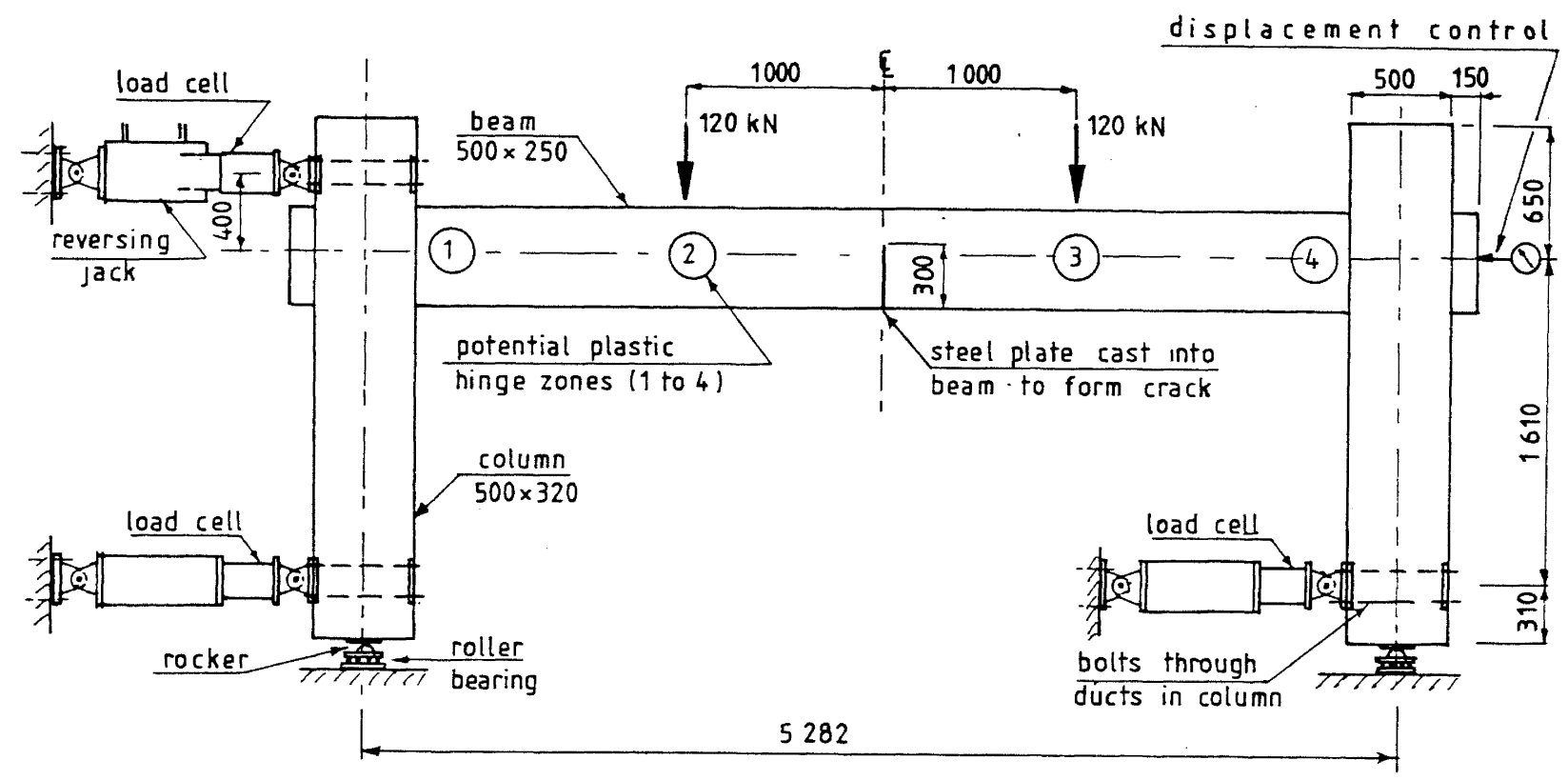

FIGURE 2. PORTAL FRAME SET -UP

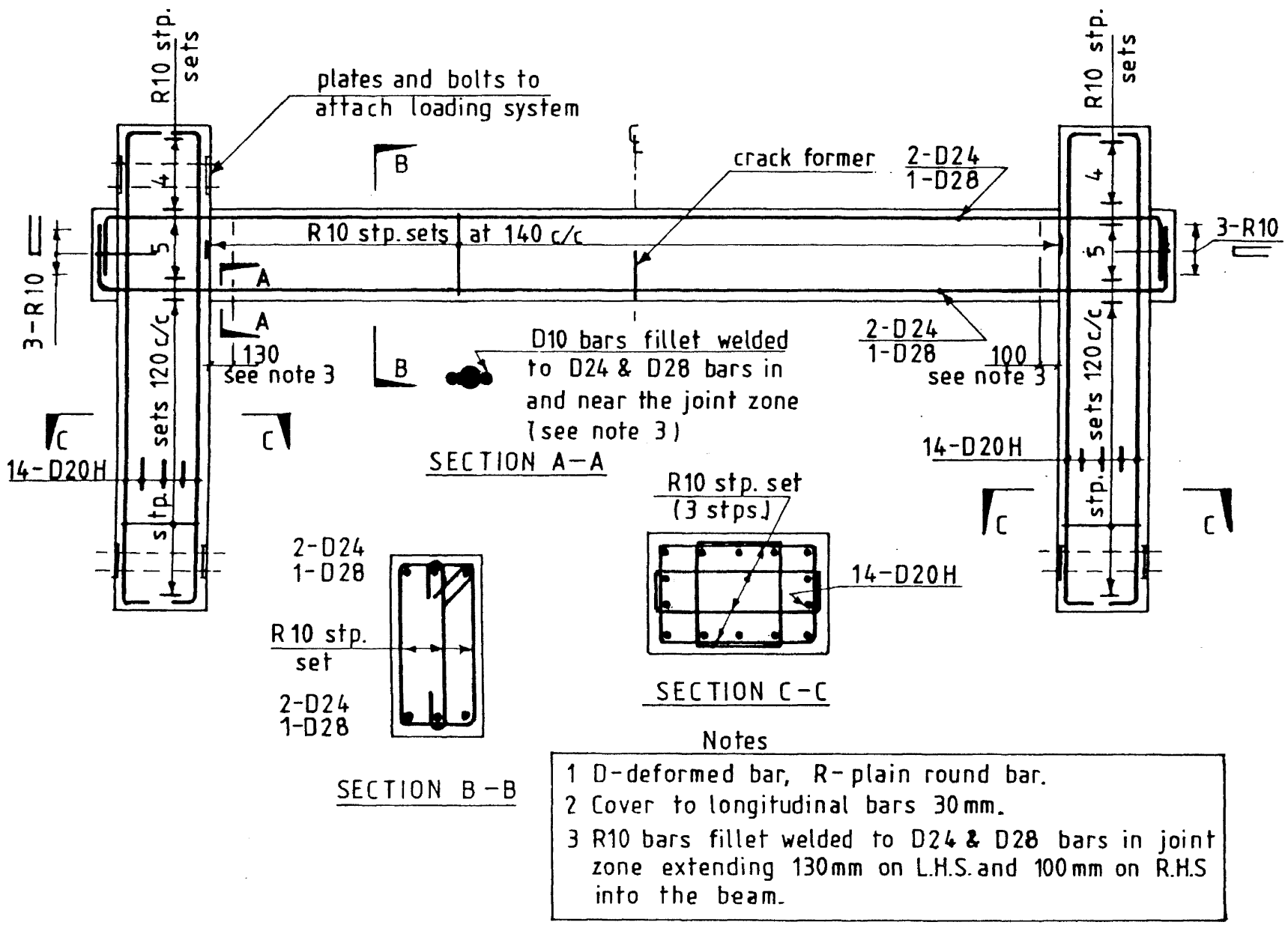

FIGURE 3. REINFORCING DETAILS 
with two cycles to plus and minus each of 2,4 and 6 times the ductility one displacement. These displacements are referred to as + or $-2 \mathrm{D}, 4 \mathrm{D}$ and $6 \mathrm{D}$ in the following text with the sign indicating the direction of displacement. To differentiate between the first and second cycles of loading the $i$ or $i i$ is added to the term (i.e. $-4 \mathrm{Di}$ ). The lateral displacement was measured at the mid height of the beam stub near the column remote from the jack (see Figure 2).

\section{INSTRUMENTATION}

Load cells were used to monitor all the loads applied to the test unit together with the horizontal reactions. Some 84 displacement transducers were mounted on the test specimen to enable the deformed shape to be measured. Most of these were attached to studs which were welded onto the reinforcement. A clear gap was left round each stud so that if the bar slipped through the concrete there was no contact made with the stud. In addition to these measurements a precise level was used to record the deflected profile of the unit during the test.
A $2 \mathrm{~mm}$ plate was cast into the tension zone of the beam at mid-span to initiate a crack. The three bottom beam bars at this point were each strain gauged by a pair of electrical resistance gauges to enable the force in the reinforcement to be assessed during the test. These bars were calibrated in axial tension tests before the concrete was cast.

\section{HINGE FORMATION}

In the first inelastic displacement to stage +2Di a plastic hinge formed at the unloaded end, hinge 4, as shown in Figure 2 . When the load direction was reversed to $-2 \mathrm{Di}$ the corresponding hinge at the lefthand column face (hinge 1) formed together with a hinge under the right-hand vertical load (hinge 3 ). The rotations sustained in the hinges 1,3 and 4 generally increased throughout the loading sequence, as is shown in Figure 4 . In the $6 \mathrm{D}$ load cycles peak rotations in these plastic hinges exceeded $0.08,0.06$ and 0.07 radians. However hinge 2 under the left-hand vertical load did not continue to develop after the $4 \mathrm{Di}$ cycle, only reaching a

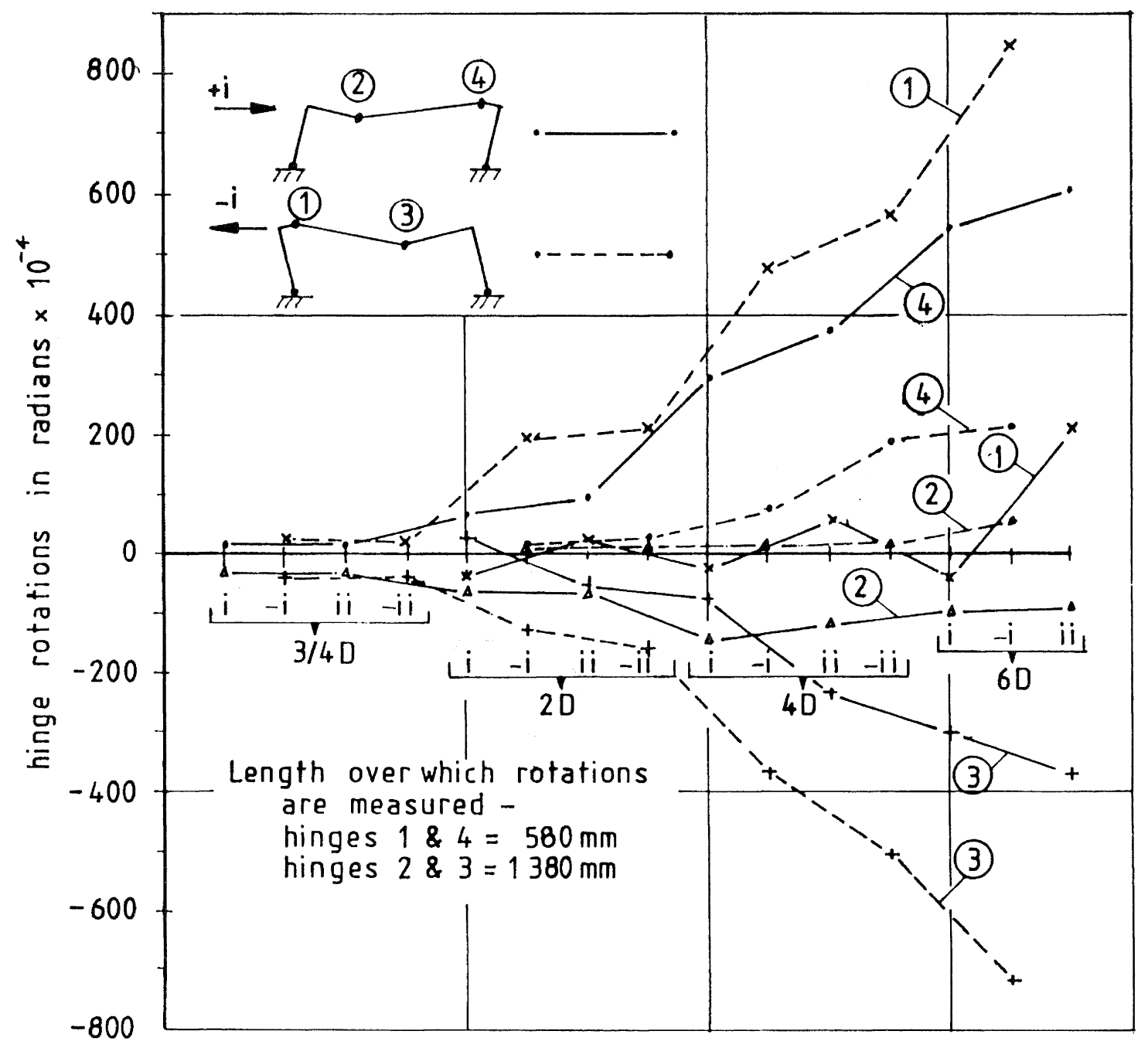



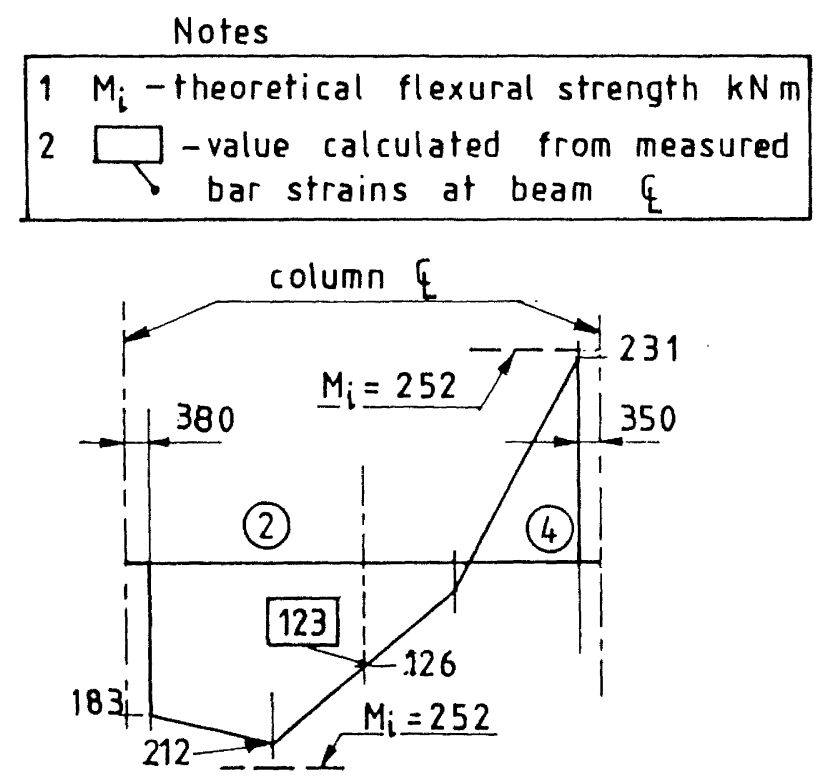

(b) 2Di peak displacement

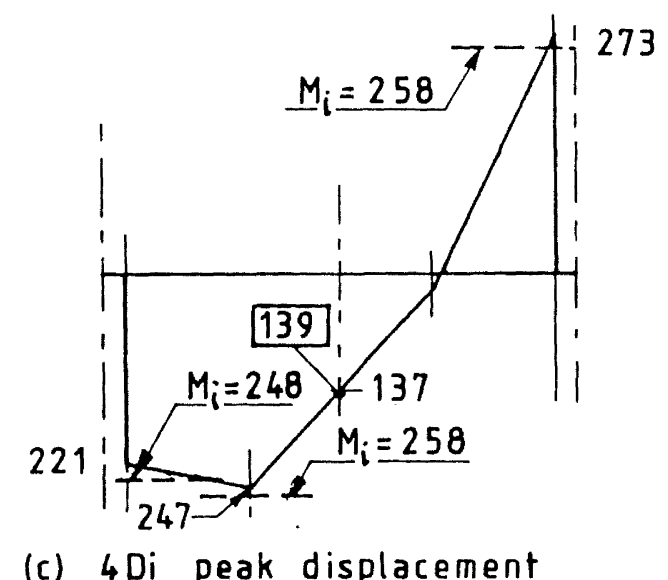

(c) $4 \mathrm{Di}$ peak displacement

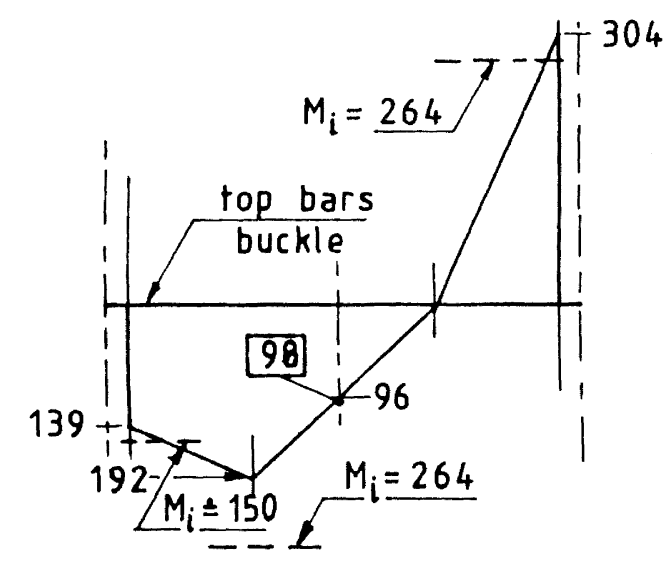

(d) $6 \mathrm{Di}$ peak displacement

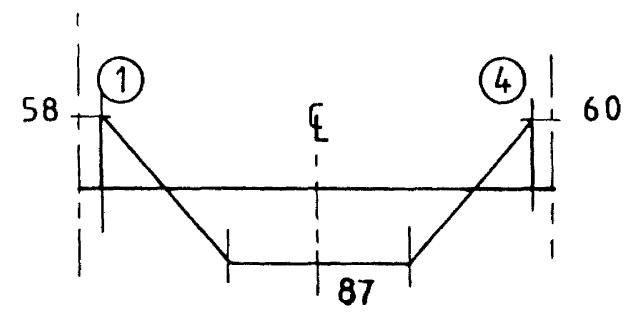

(a) Vertical loads applied

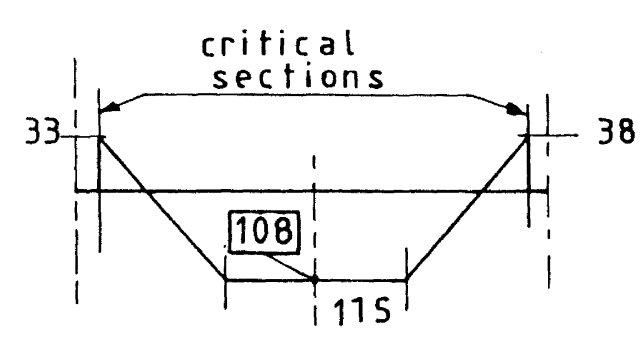

Lateral load removed potential plastic hinge zones

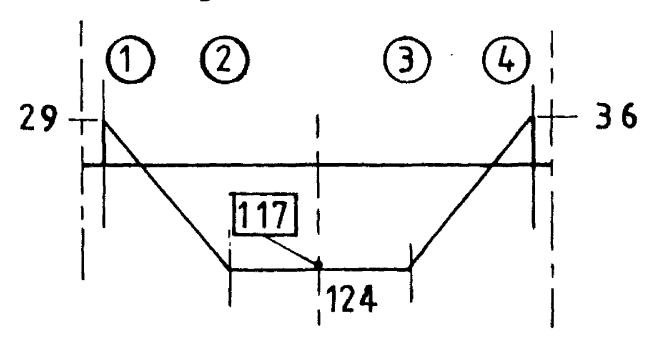

Lateral load removed

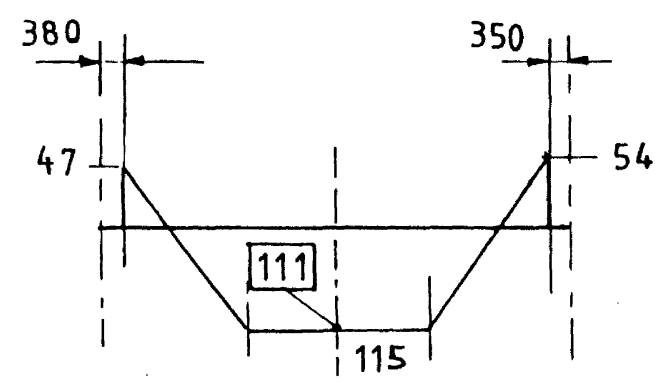

Lateral load removed 


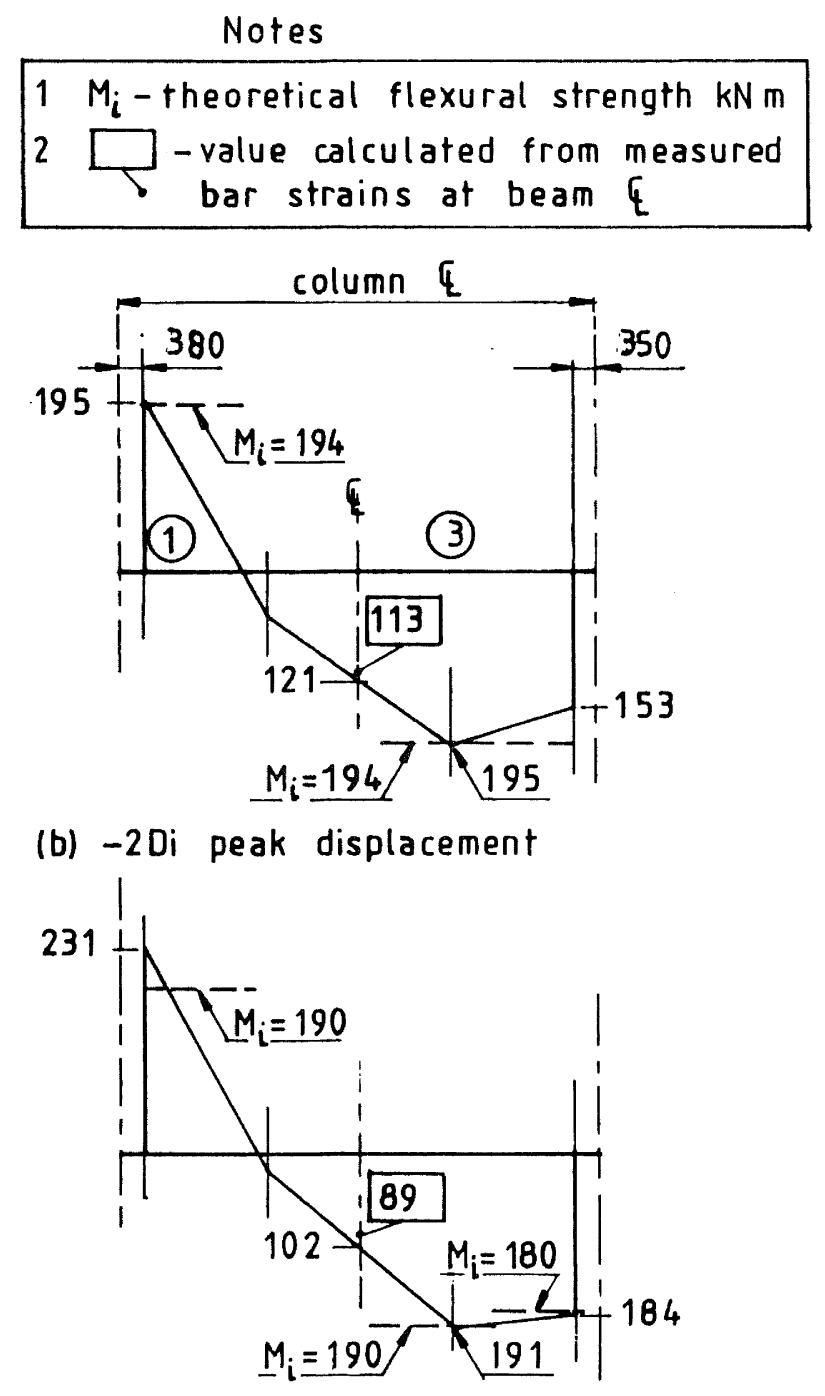

(c) $-4 \mathrm{Di}$ peak displacement

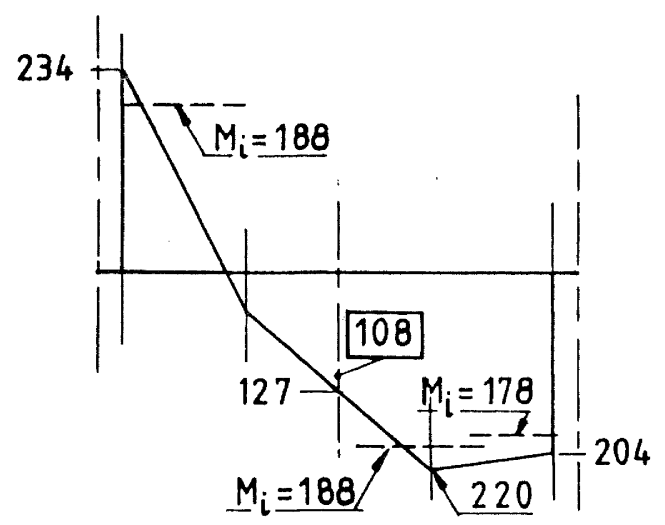

(d) $-60 \mathrm{i}$ peak displacement

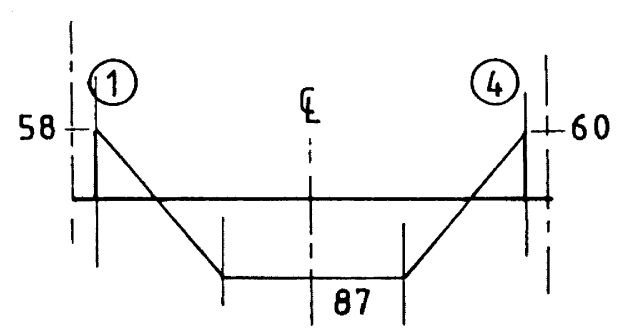

(a) Vertical load applied

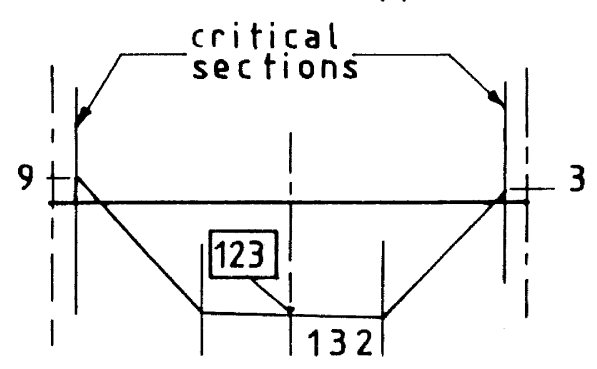

Lateral load removed

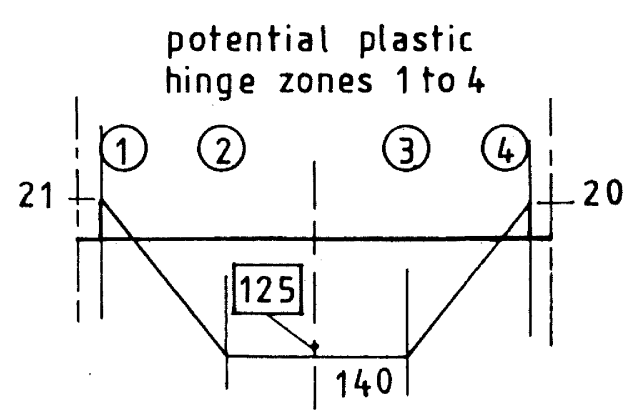

Lateral load removed

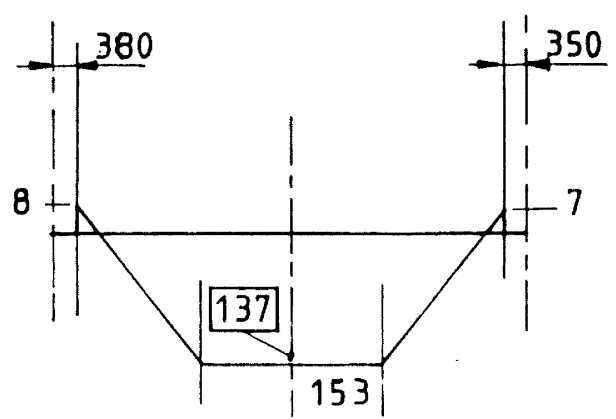

Lateral load removed 
maximum rotation of about 0.015 radians throughout the test.

The reason for this non symmetrical behaviour of the portal arises from two causes. The first of these is due to the loading system used. Under positive loading, when the portal is being pushed out from the wall, the beam is subjected to axial compression, which increases the flexural resistance of the hinge zones. The reverse condition exists under the second half of the loading cycle when the beam is subjected to axial tension. The second cause arises from the change in flexural resistance of a member due to the prior tensile yielding of reinforcement in the compression zone. The open cracks associated with this yielding must be closed before the concrete can resist any compression force, consequently a greater proportion of this force is resisted by the reinforcement than is predicted by standard flexural theory. With the beam under consideration this led to a reduction in the internal lever arm and the flexural resistance.

To investigate the significance of the pretensile yielding of the reinforcement in the compression zone on the flexural strength, two moment axial load interaction diagrams were constructed for the beam under flexure and axial load. In the first of these the interaction diagram was calculated from structural flexural theory. In the second the centroid of the compression force was assumed to be coaxial with the centroid of the compression reinforcement. This case is believed to correspond to the previous tensile yield situation of the compression zone reinforcement. Both axial load and bending moment interaction curves were linear over the range of axial load in the beam during the test $(122 \mathrm{kN}$ tension to $239 \mathrm{kN}$ compression). For any axial load in this range the reduction in theoretical moment strength was about $10 \mathrm{kNm}$ for the previous tension yield of the compression zone reinforcement case compared with the standard flexural theory curve. In Figure 5 the experimentally determined bending moments, which have been calculated from the measured reactions and applied loads, are compared with the theoretical strengths. These neglect strain hardening. Unless the compression zone reinforcement has been pre-yielded in tension the theoretical value has been taken from the standard flexural theory interaction diagram. Where this condition is not met the other interaction curve was used.

In cycles $2 \mathrm{Di}$ and $2 \mathrm{Dii}$ (see Figure $5 \mathrm{~b}$ for the $2 \mathrm{Di}$ situation) the reinforcing strains showed that hinge 2 was close to forming over a distance from the load point to the critical section. This section was where the extra Dlo bars welded to the beam steel terminated, $130 \mathrm{~mm}$ out from the column face. In the $4 \mathrm{Di}$ cycle the strain measurements indicate that the bottom steel yielded over most of the length from critical section to the load point, though in Figure $5 \mathrm{c}$ it would appear that the bending moments were a few percent below the theoretical ultimate values. The first yield moment would be slightly less than the theoretical ultimate bending moment because of the different concrete stress blocks. This long hinge length was due to the flat nature of the bending moment diagram in this region, the slightly smaller moment strength at the critical section because of the pre-yielded in tension compression steel and the softening of the reinforcing due to the Bauschinger effect. During cycle 6Di (Figure 5d) the top steel near the column (hinge 1) buckled and the strength shown $(150 \mathrm{kNm})$ is approximately that for the beam with the compression steel buckling over a length of about $240 \mathrm{~mm}$. The cover concrete had spalled and the beam steel buckled over roughly twice the stirrup spacing, badly distorting the stirrups in the process.

The actions at the mid span section of the beam were monitored by strain gauges on the reinforcement. These readings have been used to calculate the elastic bending moment sustained by the section, and the value obtained this way is compared with the experimental bending moment diagram.

\section{MOMENT REDISTRIBUTION}

Moment redistribution of the beam column face moments did occur during testing as seen in Figures $5 a, 5 b, 5 c$ and $5 d$. Figure $5 \mathrm{a}$ are the beam moments at the test start with the initial $110 \mathrm{kN}$ vertical loads applied and Figures $5 \mathrm{~b}, 5 \mathrm{c}$ and $5 \mathrm{~d}$ are the moment diagrams immediately after cycles $2 \mathrm{Di}, 4 \mathrm{Di}$ and $6 \mathrm{Di}$ respectively, the lateral load having been removed. These moment diagrams were calculated from the actual measured loads and reactions on the frame, while the mid-span moment shown in the box was calculated from the strains and hence stresses measured in the bottom beam bars. The corresponding bending moment diagrams after the $-2 \mathrm{Di},-4 \mathrm{Di}$ and $-6 \mathrm{Di}$ lateral load removal are shown in Figures $6 \mathrm{~b}, 6 \mathrm{c}$ and $6 \mathrm{~d}$ respectively. When compared with the original moment diagram (see Figure 6a) it can be seen that substantial redistribution of gravity actions occurred.

\section{BEAM SAGGING AND LENGTHENING}

Two significant effects were caused by the plastic hinges not reversing and accumulating plastic rotations in one direction as the structural ductility was increased; firstly the beam increasingly sagged in the mid-span region and secondly the beam increased in length. Figure 7 shows the mid-span beam vertical deflections progressively increasing during the test. A deflection of $43 \mathrm{~mm}$ was reached in the second reverse cycle to ductility 4 ( $-4 \mathrm{Di}$ ) which represented 0.009 of the beam's clear span. At failure (near -6Dii) this deflection had almost doubled to $79 \mathrm{~mm}$.

In Figure 8 the increase in beam length at each cycle peak is shown. These were found directly from the measurements taken at the beam centreline at both ends of the frame. The portal transducers along the beam indicated that the strains in the compression reinforcement were small. This suggested that the growth in length of the beam might be predicted by assuming that 


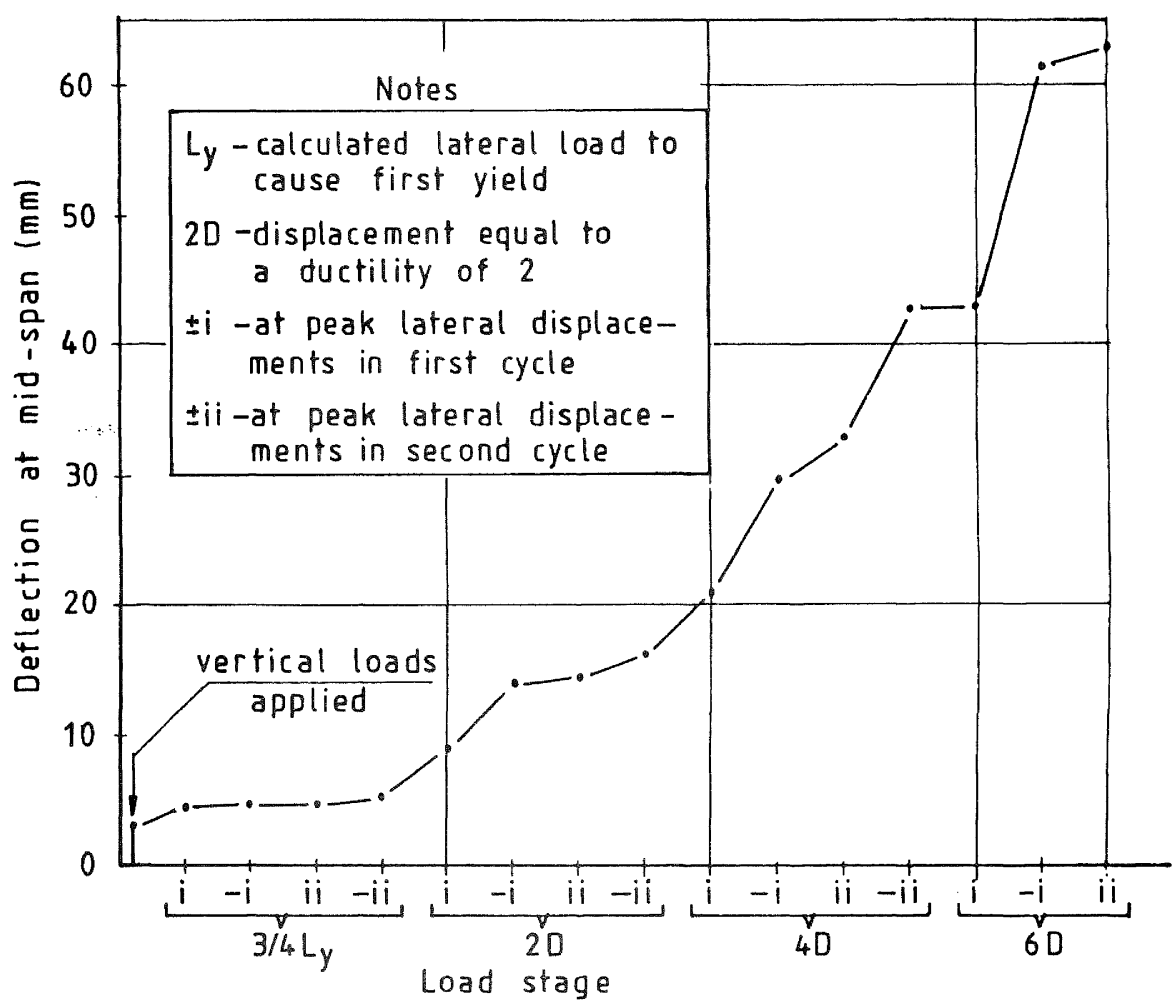

FIGURE 7. MID-SPAN BEAM DEFLECTION
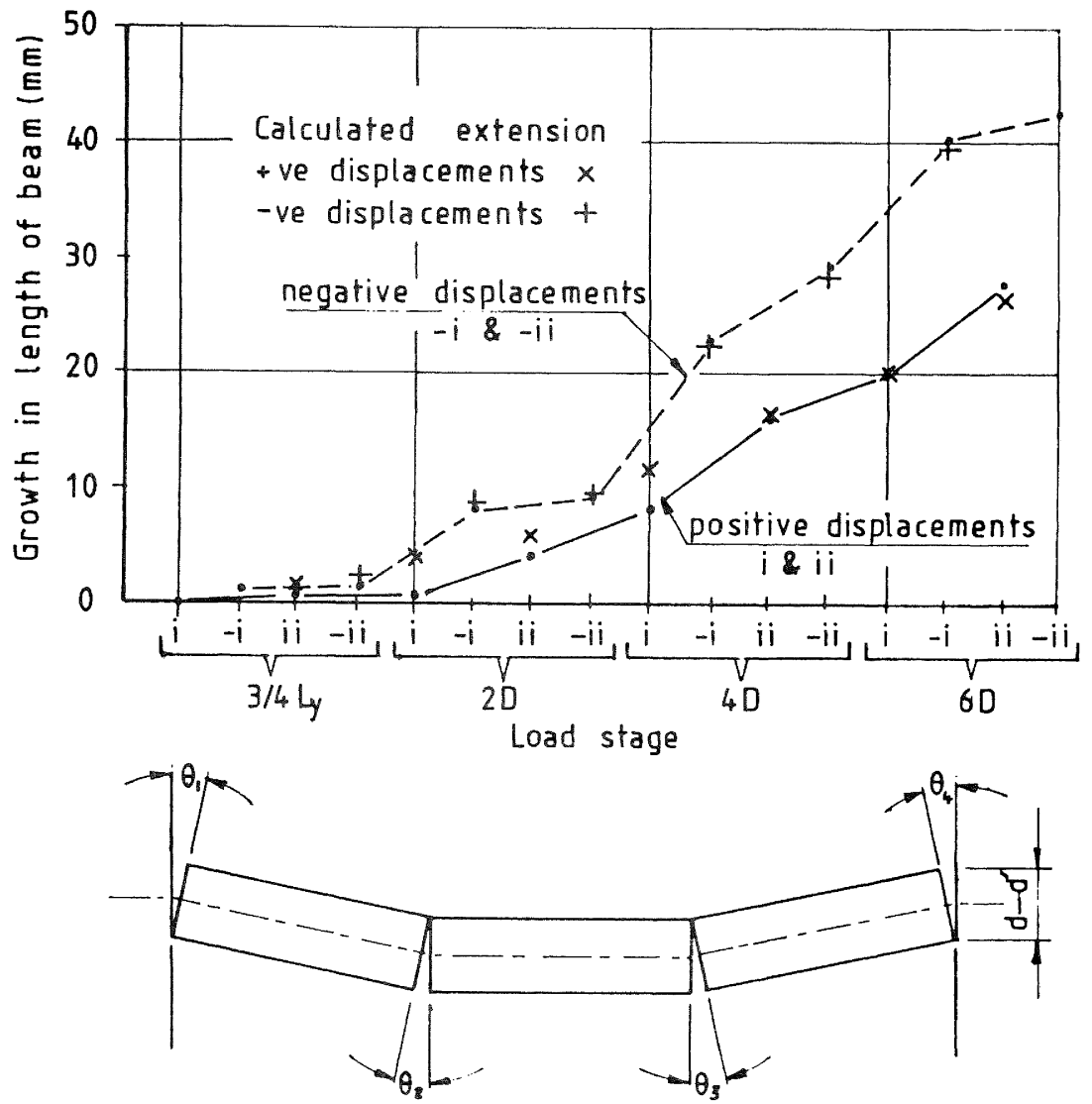

$\left.\begin{array}{c}\text { Calculated extension of beam } \\ \text { on mid-depth line }\end{array}\right]=\sum_{1}^{4} \theta\left(d-d^{\prime}\right) / 2$

FIGURE 8. GROWTH IN BEAM LENGTH 


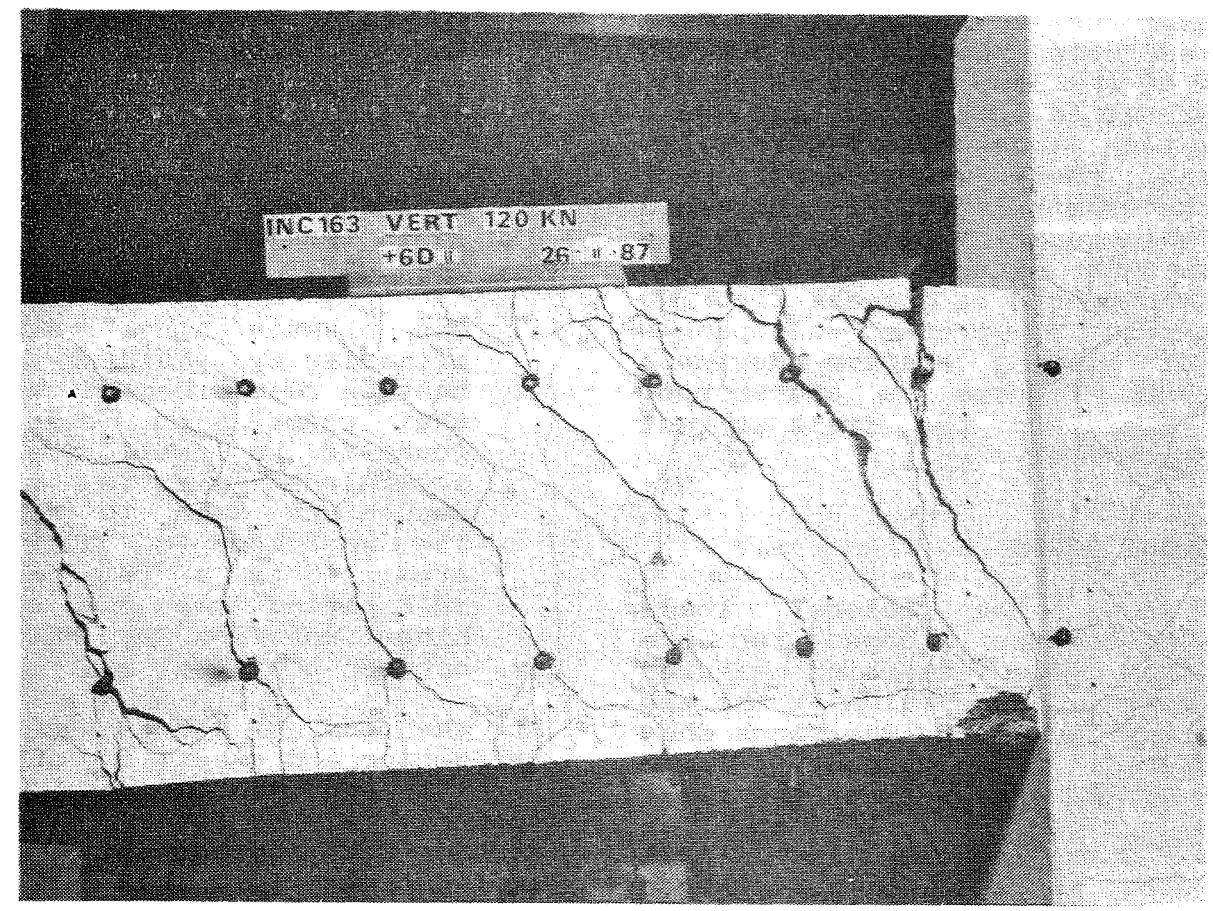

FIGURE 9A. HINGE \& AT CYCLE +6DII

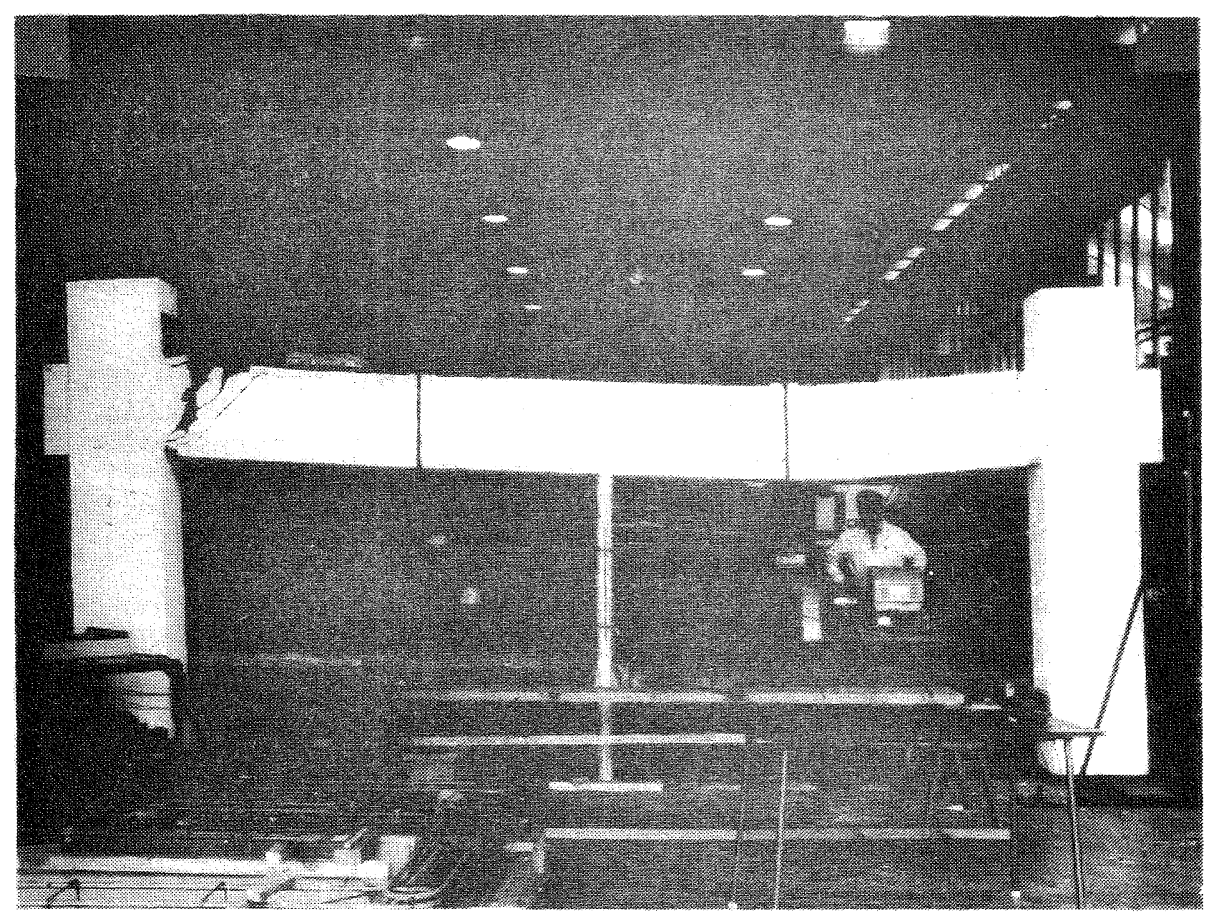

FIGURE 9B. PORTAL AT COMPLETION OF TEST 
compression strains in the reinforcement were negligible and that the plastic hinge rotation was due to yielding of the tension steel. With this assumption the growth in length is equal to the sum of the beam rotations times half the distance between the centroids of the top and bottom steel. The values determined in this way are shown as the calculated values in Figure 8 . At most cycle peaks there was good agreement and at $-6 \mathrm{Di}$ the beam's length had increased by $40 \mathrm{~mm}$ ( $0.8 \%$ increase). Beam sagging and lengthening to this extent could mean the failure of the supports of precast flooring systems, battering of precast wall panels and failure of glazing systems during a major earthquake. Figures $9 \mathrm{a}$ and $9 \mathrm{~b}$ show hinge 4 at $+6 \mathrm{Dii}$ and the frame at test completion respectively.

\section{LOAD DISPLACEMENT LOOPS}

Figure 10 shows the lateral loaddisplacement hysteresis loops for the portal frame, the deflection being measured at the beam centreline elevation at the end away from the applied load. The loops show good repeatability, without large reductions in stiffness between the first and second cycles at 2D and 4D displacements. Some increase in lateral load is evident in the 4D cycles when compared with the 2D cycles. This was due to strain-hardening of the reinforcement. The load deflection characteristics showed unusually little stiffness degradation until the 6D load cycles. During the 6Di cycle there was a large loss in stiffness and a reduction of about $14 \%$ in the lateral load resistance. This was associated with the spalling of the cover concrete in the compression zone and buckling of the compression bars at hinge 1 . Just prior to the -6Dii load stage failure occurred near the column face.

\section{CONCLUSIONS}

A reinforced concrete portal frame was built and tested to study the seismic behaviour of multi-storey frames which are resisting appreciable gravity loads. In the test two constant point loads were applied to the beam while cyclic lateral loads were applied to the frame to represent earthquake loading.

With the cyclic loading negative moment plastic hinges formed in the beams close to the column faces and positive moment hinges formed in the beam span. The hinges were of the "non-reversing type", in which each inelastic lateral displacement caused the hinge rotations to increase in one direction. There are a number of important structural effects arising from this type of behaviour.

1. The plastic hinge rotation demand is related to the sum of all the inelastic displacements occurring in one direction. The maximum displacement ductility, which is usually used as a guide to seismic design, has no direct relationship to this value.

2. The formation of the plastic hinges led to the redistribution of the bending moments associated with the vertical (gravity) loads as predicted in a previous paper [1].

3. The increasing hinge rotations sustained as the test progressed were reflected in increasing vertical deflections of the beam.

4. The plastic hinge rotation occurred primarily by yielding of the flexural tension reinforcement while strains in the compression reinforcement were found to be small. Due to this the accumulated plastic hinge rotations caused the beam to expand in length. The magnitude of this expansion was predicted to a reasonable accuracy by multiplying the sum of the absolute hinge rotation by half the distance between the steel centroids.

At the end of the test the vertical deflection and growth in length of the beam were 77 and $42 \mathrm{~mm}$ respectively, that is approximately 15 and 8 percent of the beam depth. Such deformations have serious implications for the survival of frame structures which form this type (gravity dominated) of beam sway mode. Where several bays are in one frame the exterior columns at the ground floor level must be subjected to high shears and high deformation, which have important effects on localised $\mathrm{P} \Delta$ and hinge rotation demands in the column. The high beam deflections and expansions in length in each bay have serious implications for the survival of the fixing details for precast flooring and cladding units to the structure.

Further research is required to identify what inelastic demand buildings should be designed to sustain in a major seismic event (major earthquake and aftershocks). The current NZS 4203 criteria, which defines ductile structures as those that can sustain four cycles to displacements of plus and minus four displacement ductilities, provides a very severe test for frames that form the type of beam sway mode described in this paper. Many of our current structures and their fixings are likely to be severely distressed if in reality subjected to a comparably severe sequence of loading.

\section{REFERENCES}

1. Fenwick, R. C. and Davidson, B.J. 1987. Moment redistribution in seismic resistant concrete frames, Proceedings of the Pacific Conference on Earthquake Engineering, Wairakei, New Zealand, vol. 1, pp95-106.

2. Standards Association of New Zealand. 1982. Code of practice for the design of concrete structures, NZS 3101, Wellington. 


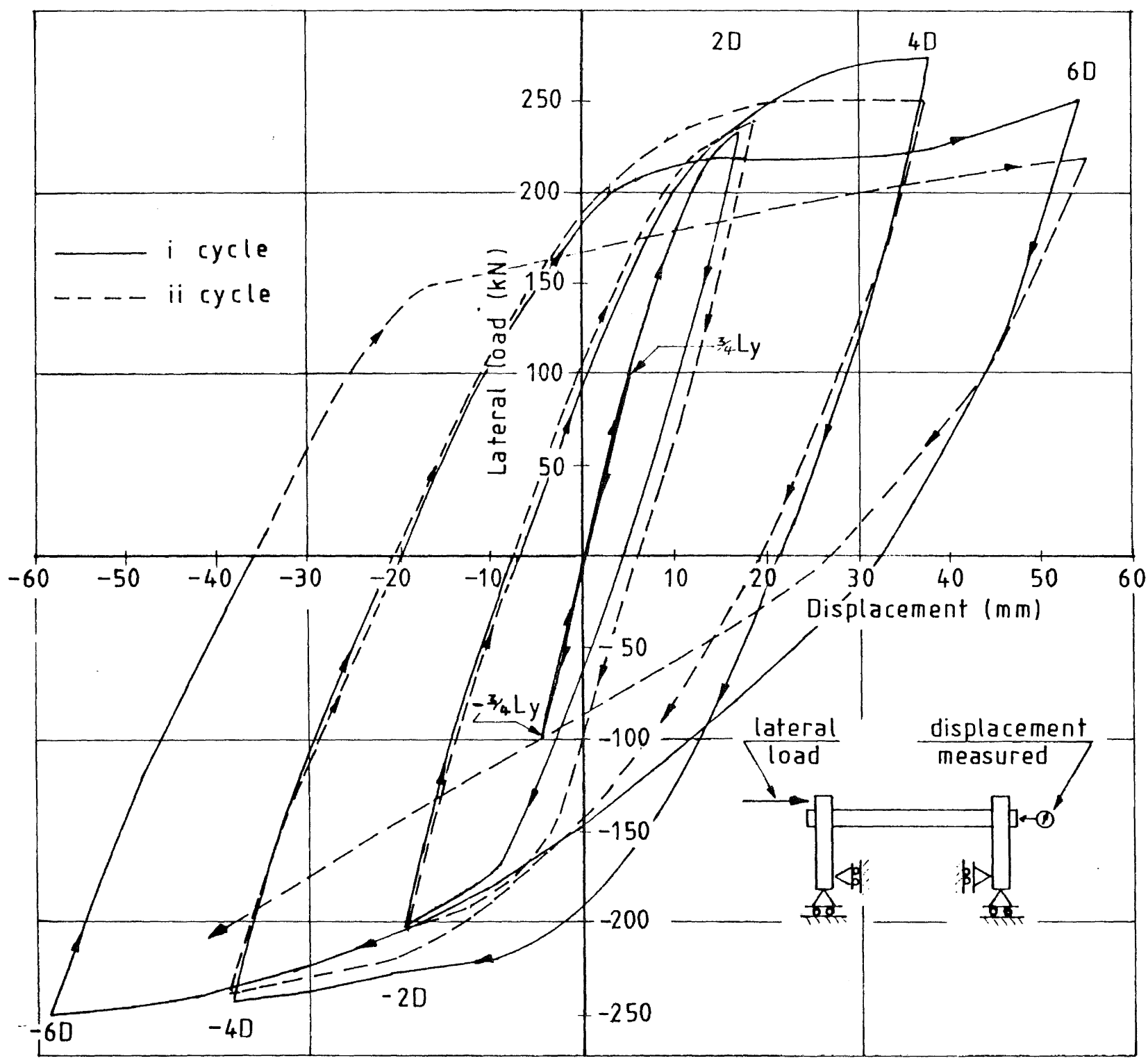

FIGURE 10. LATERAL LOAD-DISPLACEMENT LOOPS 